\title{
Are Orthopaedic Surgeons being Adequately Compensated for Ankle Fractures? - An Analysis of Relative Value Units
}

Azeem Tariq Malik, MBBS, Safdar N Khan, MD, Laura Phieffer, MD, Thuan V Ly, MD, Carmen E Quatman, MD, PhD

The OHIo STATE

UNIVERSITY

WEXNER MEDICAL CENTER

\section{Introduction}

The current RVU-based system is built to reflect the varying presentation of ankle fractures (uni-malleolar vs. bi malleolar vs. tri-malleolar) by assigning individual RVUs to different fracture complexities. However, no study has evaluated whether the current RVUs reflect an appropriate compensation per unit time following open reduction internal fixation (ORIF) for uni-malleolar vs. bi-malleolar vs. tri-malleolar ankle fractures.

\section{Objectives}

- To analyze differences in 1) mean total RVU, 2) mean RVU/min, 3) reimbursement rate $(\$) / \mathrm{min}$ and 4 ) total reimbursement per case between uni-malleolar, bi-malleolar and tri-malleolar ankle fractures.

\section{Methods}

- 2012-2017 ACS-NSQIP Database

- $\quad$ Adult patients aged $>18$ years

- Patients undergoing ORIF for isolated uni-malleolar, bimalleolar and tri-malleolar isolated ankle fractures.

\section{Outcomes Studied}

- Mean total RVU = Work RVU + other associated procedure RVUs

- Mean total operative time (mins)

- Mean RVU/min = RVU/total operative time

- Reimbursement rate $(\$ / \mathrm{min})=\mathrm{RVU} / \mathrm{min} X \$ 35.887 / \mathrm{CMS}$ conversion factor

\section{Results}

- A total of 21,047 isolated ankle fractures included - 7,830 (37.2\%) were uni-malleolar

$-7,826(37.2 \%)$ were bi-malleolar $-5,391(25.6 \%)$ were tri-malleolar

Table 1: Mean RVU, operative time, RVU/min and reimbursement rates for each fracture type. Comparisons made using Kruskal-Wallis tests.

\begin{tabular}{|r|c|c|c|c|}
\hline Variable & $\begin{array}{c}\text { Uni-Malleolar } \\
\text { Ankle } \\
\text { Fracture }\end{array}$ & $\begin{array}{c}\text { Bi-Malleolar } \\
\text { Ankle Fracture }\end{array}$ & $\begin{array}{c}\text { Tri-Malleolar } \\
\text { Ankle } \\
\text { Fracture }\end{array}$ & P-value \\
\hline Number & 7,830 & 7,826 & 5,391 & - \\
\hline $\begin{array}{r}\text { Mean Total RVU } \\
\text { Mean Operative }\end{array}$ & $63.99 \pm 3.39$ & $11.71 \pm 3.02$ & $12.87 \pm 3.17$ & $<0.001$ \\
\hline $\begin{array}{r}\text { Time (mins) } \\
\text { Mean RVU/min }\end{array}$ & $0.201 \pm 0.126$ & $0.188 \pm 0.139$ & $0.170 \pm 0.142$ & $<0.001$ \\
\hline $\begin{array}{r}\text { Mean } \\
\text { Reimbursement } \\
\text { Rate/min }\end{array}$ & $\$ 7.21 \pm$ & $\$ 6.75 \pm$ & $\$ 6.10 \pm$ & $<0.001$ \\
\hline
\end{tabular}

\section{Conclusion}

- Using a national surgical dataset of over 21,000 ankle fractures undergoing ORIF, the results identify and highlight significant discrepancies in the current RVU-based physician compensation model.

- Though tri-malleolar and bi-malleolar fracture types had a statistically higher RVU, this increase was not proportional of the higher operative times that goes into treated a more complex fracture type leading to lower RVUs/minute as compared to uni-malleolar fractures.

- Despite the higher complexity, effort, skill and longer operative times required in surgically treating a tri-malleolar ankle fracture, surgeons are reimbursed at a lower rate $(\$ / \mathrm{min})$ as compared to bi-malleolar and uni-malleolar ankle fractures.

- The study highlights the need of a change in the RVUs for bi-malleolar and tri-malleolar ankle fractures to ensure that surgeons are adequately reimbursed per unit time for treating a more complex fracture case. 